\title{
A Fluid-Solid-Magnetic Coupling Algorithm of Internal Crack Growth in the Weld of Oil and Gas Pipelines
}

\author{
Wei Cui $\left(\mathbb{D},{ }^{1}\right.$ Rixuan Song, ${ }^{1}$ Fafeng Xia, ${ }^{1}$ Qiang Zhang, ${ }^{1}$ and Peter Wang ${ }^{2}$ \\ ${ }^{1}$ College of Mechanical Science and Engineering, Northeast Petroleum University, Daqing 163318, China \\ ${ }^{2}$ Department of Mechanical Engineering, Seattle University, Seattle, WA 98195, USA \\ Correspondence should be addressed to Wei Cui; cuiweivv@126.com
}

Received 21 May 2018; Revised 17 July 2018; Accepted 25 July 2018; Published 3 October 2018

Academic Editor: Ricardo Branco

Copyright (c) 2018 Wei Cui et al. This is an open access article distributed under the Creative Commons Attribution License, which permits unrestricted use, distribution, and reproduction in any medium, provided the original work is properly cited.

\begin{abstract}
In order to characterize the dynamic process of the crack growth in the weld of oil and gas pipelines, a mathematical model of fluid-solid-magnetic multifield coupling was constructed in this paper. Based on this model, the bidirectional fluid-solid coupling and unidirectional magnetic structure coupling caused by the weld deformation were achieved by dynamic application of the fluid permeation pressure, calculating the internal crack growth in the pipe weld, reconstructing the computational grid near the internal crack, and discussing the characteristics of the magnetic leakage field in the process of the internal crack growth in pipe weld. Thus, a fluid-solid-magnetic coupling algorithm for the internal crack growth in pipe welds considering fluid permeation pressure is established. According to the characteristics of the internal crack opening distance, internal crack growth length, crack tip energy release rate, peak values of magnetic induction intensity level, and vertical component, the process of the internal crack growth is measured. The results show that the fluid osmotic pressure accelerates the process of the internal crack growth and this algorithm can solve the problem of the characterization and evaluation of crack growth in pipe welds under fluid-solid-magnetic coupling action.
\end{abstract}

\section{Introduction}

Oil and gas pipelines are important ties to connect the production, transportation, and marketing as the transportation tool of petroleum and natural gas. Petroleum and natural gas both belong to state key supervision hazardous chemicals, which are inflammable, explosive, and toxic substances. Hence, it is easy for them to cause the accident of fire and explosion upon leakage and ignition source. In addition, the oil and gas pipeline used for transporting oil and gas resources are a major hazard because of the long pipeline, high pressure, and changeable environment. Hence, the safety management, detection, and protection of oil and gas pipelines are key technologies that are involved in the prevention and control of national production accidents. In the leakage and explosion accidents of oil and gas pipeline, one of the most critical risk factors affecting its safety is the cracking of the pipe weld. Many catastrophic accidents originate from the rapid expansion of the crack under the internal pressure of the pipeline fluid, and the cracking of the pipeline is a dynamic process. Therefore, the research on detecting and evaluating the in-service inspection of weld crack propagation is very important in the field of engineering practice. Besides, the magnetic flux leakage (MFL) technology which was originated from 1960s integrates nondestructive testing, magnetic physics, and metallography and has been widely used to detection in the storage tank and pipelines because of its high accuracy, reliability, and easy automation $[1,2]$.

Because the fluid penetration pressure has a direct impact on the crack in the inner wall of the pipe, it is more dangerous than that caused by the outer wall crack. When there is defect damage on the inner wall of the weld of pipelines, the propagation of the crack defect is aggravated under the erosion of the fluid due to the space of the pipeline weld joint where the leakage defect of the conveying fluid is located, which is the fluid-solid coupling effect between the defect-space contact surface of the inner wall of the pipeline weld seam and the conveying fluid. During MFL detection, such defect expansion is caused by fluid-structure interaction between the defect-space contact surface in inner wall of the 
weld and the transporting fluid, and this is also accompanied with multifield coupling problem of magnetic force fields. Many researches about the fluid-solid coupling in pipelines have been reported. Professor Zheng Jinyang et al. proposed a fluid-solid coupling algorithm with computational stability to investigate the fluid-solid coupling problem of deformation and fracture in pipeline explosion consequences simulation [3]. Professor Feng Weimin et al. analyzed the fluid-solid coupling phenomenon of pressure pipelines and constructed the finite-element mathematical model of fluid-solid coupling, simulated the transition process caused by valve switch by using the finite-element software ADINA, and performed the numerical simulation calculation to fluid-solid coupling phenomenon of straight pressure pipelines under different constraints [4]. However, there are few research papers reported on the fluid-solid-magnetic multifield coupling studies by using the application of magnetic force field. E. Aursand et al. developed a coupled fluid-structure interaction model, which consisted of a homogeneous equilibrium flow model, coupled with the Span-Wagner equation of state and including solid-phase formation, and a finite-element model of the pipe taking into account large deformations and fracture propagation through a local fracture criterion [5]. H. O. Nordhagen et al. modeled the pipe material and fracture propagation using the finite-element method with a ductile fracture criterion. The finite-volume method has been employed to simulate the fluid flow inside the pipe, and the resulting pressure profile was applied as a load in the finiteelement model. Choked-flow theory was used to calculate the flow through the pipe crack [6].

The preliminary experimental research on different degrees and positions of typical cracking defect in the weld of oil and gas pipelines was carried out, and the magnetic induction intensity distribution in the leakage magnetic field caused by the pipe weld cracks was obtained, and then the surface remanufacturing was studied $[7,8]$. However, this study only involved the static MFL testing of the weld cracks of pipelines. The research on the dynamic MFL in the crack growth process was not discussed in detail. Therefore, a simulation algorithm of the internal crack growth in the weld of oil and gas pipelines based on the fluid-solid-magnetic multifield coupling was established in this paper. And this algorithm could achieve the detection of internal cracks in the weld of serving pipelines by using MFL technique and characterize and evaluate the internal crack growth in the weld of pipelines under the fluid-solid-magnetic multifield coupling effect. The realization of the algorithm can provide a theoretical basis for the detection and evaluation of weld cracks in-service pipeline by using MFL method and the remanufacture, repair, or replacement of oil and gas pipelines.

\section{Fluid-Solid-Magnetic Multiphysical Field Model}

According to the principle of MFL detection of pipeline weld [7], the fluid-solid-magnetic multiphysical field model of internal crack growth in the weld of pipelines was constructed. Firstly, the structural model of weld was set up.

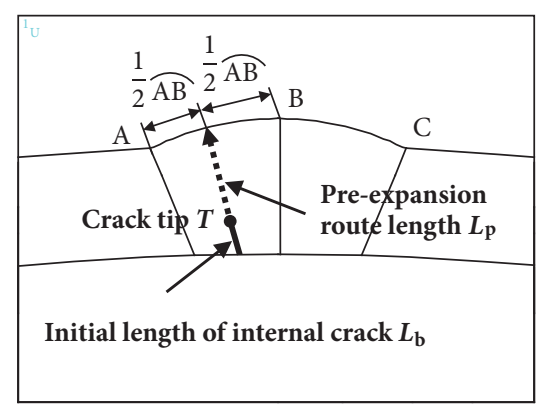

FIGURE 1: Diagram of the initial internal crack of pipe weld.

According to the material and parameters of the pipe weld (such as pipe diameter $D$, pipe wall thickness $W$, weld reinforcement height $W_{r}$, and weld width $W_{w}$ ), the stress analysis model of the weld structure of pipelines was established with the plain strain model and the two-dimensional PLANE182 structural unit in finite-element software. Secondly, the initial internal crack was defined in advance. The initial length of internal crack was $L_{b}$ and the position of crack tip was $T$. The expansion route was defined in advance from $T$ to the weld center on the outer wall of pipelines along the radial direction. The preexpansion route length was $L_{p}$. As shown in Figure 1, the internal crack distribution along the radial inner wall was calculated by taking the position of $1 / 2$ arc length from the fusion line to the center of the welding path as an example. $L_{\mathrm{p}}$ was discretized into INTER202 unit. And at INTER202 unit, TARGE169 was chosen as the target unit and CONTA171 was chosen as the contact unit to create the contact relationship.

After that, the excitation structural model outside the pipelines was constructed. According to the structural size, the weld and excitation structural model of pipelines is shown in Figure 2. In the excitation structure, Nd-Fe-B was chosen as the permanent magnet and ingot iron was used as armature and pole shoes. The two-dimensional PLANE13 magnetic field unit was applied to construct the magnetic field analysis model for the excitation structure according to the excitation structural size. Fluids at internal cracks in pipelines and weld were discretized into the two-dimensional PLANE13 magnetic field unit, and the outer spaces of the weld and surrounding air domain of excitation structure were discretized into the two-dimensional PLANE13 magnetic field unit. Subsequently, the fluid-solid-magnetic multifield coupling finite-element gridding map of internal crack growth in the weld of pipelines was established (Figure 3).

\section{Mathematical Model of Fluid-Solid-Magnetic Multifield Coupling}

3.1. Mathematical Equations. In the multiphysical field model, unit discretions of structure and magnetic field were independent mutually. The fluid-solid-magnetic multifield coupling was constructed to realize subsequent coupling 


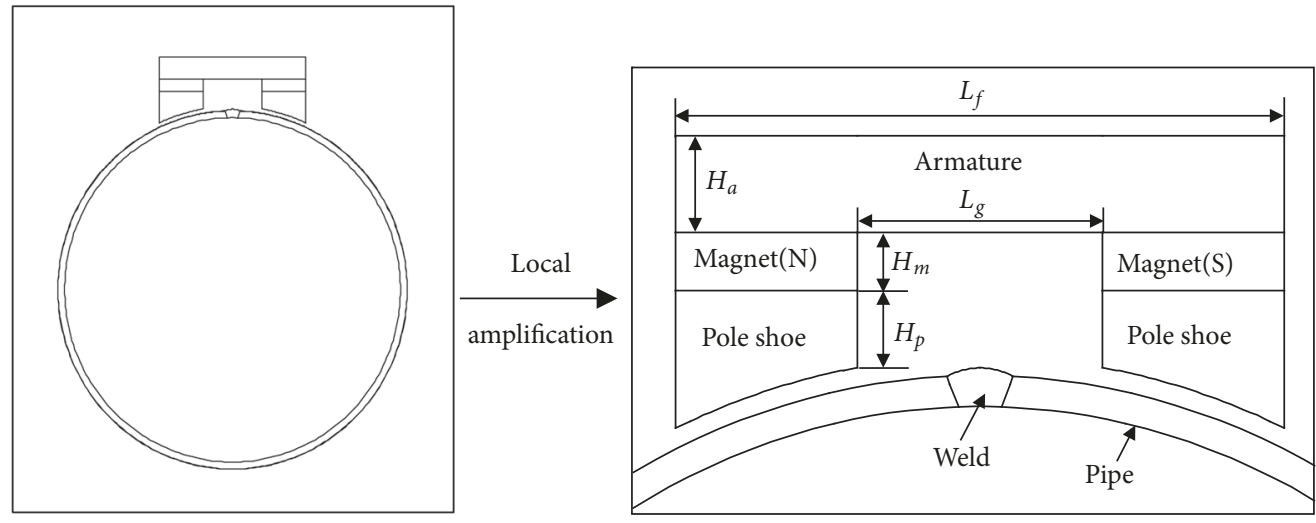

Figure 2: Excitation structural model.

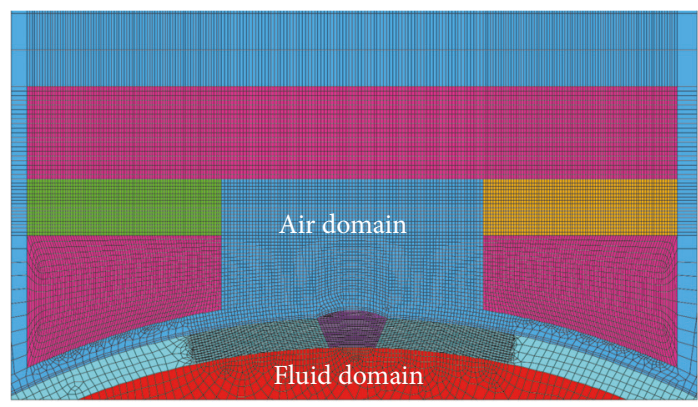

FIGURE 3: Finite-element gridding map of the fluid-solid-magnetic coupling.

calculation of internal crack growth in the weld. The construction process was as follows.

(a) The Fluid-Solid-Magnetic Multifield Coupling FiniteElement Equation Was Established

$$
\left[\begin{array}{cc}
\boldsymbol{K} & 0 \\
0 & \boldsymbol{K}_{\mathrm{m}(u)}
\end{array}\right]\left\{\begin{array}{l}
\boldsymbol{u} \\
\boldsymbol{A}
\end{array}\right\}=\left\{\begin{array}{c}
\boldsymbol{F}_{(u)} \\
\boldsymbol{\psi}
\end{array}\right\}
$$

where $K$ is the stiffness matrix of structure, $u$ is the displacement vector of nodes, $F_{(u)}$ is the load vector of nodes, $K_{\mathrm{m}(u)}$ is the magnetic stiffness matrix, $A$ is the magnetic potential vector of nodes, and $\psi$ is the magnetic flux density matrix.

$F_{(u)}$ in (1) is expressed as follows:

$$
\boldsymbol{F}_{(u)}=\boldsymbol{F}_{P i(u)}+\boldsymbol{F}_{\operatorname{mg}(u)}
$$

where $\boldsymbol{F}_{P i(u)}$ is the fluid pressure load on the inner wall and at the internal crack of pipelines and $\boldsymbol{F}_{\mathrm{mg}(u)}$ is the magnetic load.

(b) The Bidirectional Fluid-Solid Coupling Form Was Proposed and the Fluid Pressure Load Was Applied Dynamically. With the internal crack growth on inner wall of pipelines, fluid penetrated into cracks and fluid osmotic pressure was generated. The application of $F_{P i(u)}$ in (2) accelerated the internal crack growth, which caused deformation of the weld structure. The displacement vector of nodes $(u)$ was changed accordingly. As a result, the internal cracks propagated synchronously after structural deformation and further permeation of fluid, which influenced distribution of $F_{P i(u)}$ and further reaccelerated growth in the internal crack. The pressure distribution of the fluid was a dynamic process with the growth of the internal crack, $\boldsymbol{F}_{P i(u)}$ was the function of pipeline displacement $(\boldsymbol{u})$, and $\boldsymbol{F}_{P i(u)}$ was also applied dynamically. This was the bidirectional fluid-solid coupling process between internal fluid and weld structure of pipelines, which was also known as the strong coupling relationship.

(c) The Unidirectional Magnetic Structural Coupling Form Was Proposed. During internal crack growth in the weld of pipelines, fluid domain in internal cracks in the pipelines and the weld as well as outer spaces of the weld and surrounding air domain of excitation structure changed. Changes of $u$ affected magnetic field distribution in the weld of pipelines during the internal crack growth. $K_{\mathrm{m}(u)}$ in (1) was the function of $u$. Magnetic force of the magnetic field influenced the weld structure of pipelines slightly, and $F_{\mathrm{mg}(u)}$ in (2) could be neglected. This was the unidirectional magnetic coupling process from the weld structure to the magnetic field, and it was known as the weak coupling relationship.

3.2. VCCT Technique. There are three cracking modes or types of structural material cracks under the external loads, which are opening mode, sliding mode, and shearing mode. In the opening mode (usually called Mode-I crack), the external load is perpendicular to the crack plane, and the crack tip opens along the direction which is vertical to the external load. Longitudinal crack of a cylindrical shell under hoop tensile stress is one of Mode-I cracks. In this study, the longitudinal direction weld crack of the oil and gas pipeline which is developed from the circumferential tension stress caused by the fluid pressure is a Mode-I crack.

In fracture mechanics, the fracture criterion includes stress intensity factor criterion $K_{i}<K_{i c}(i=\mathrm{I}$, II, III), energy release rate criterion $G_{i}<G_{i c}(i=\mathrm{I}$, II, III), j-integral criterion $J_{I}<J_{I C}$, and CTOD (crack tip opening displacement) criterion CTOD $<\delta$. The energy release rate criterion was applied to judge the crack propagation in this study [9]. 


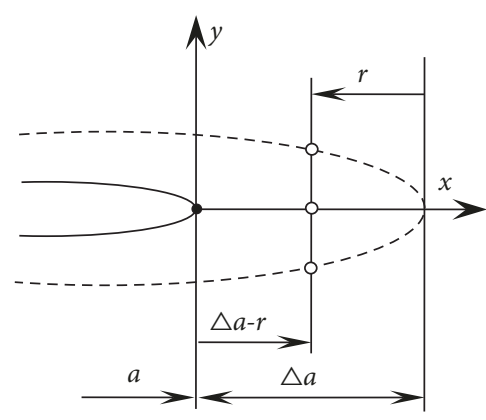

FIGURE 4: Diagram of the virtual crack closure method.

Nowadays, many scholars all over the world have proposed several FEM-based numerical methods for computing the strain energy release rate, and virtual crack closure technique (VCCT) is the most typical one based on fracture mechanics and it is an important tool for studying crack growth. In the FEM model of the cracked pipe weld in this study, VCCT was applied to compute the strain energy release rate $G$, which was a metric parameter of fracture toughness denoting the energy rate of crack growth [10-14].

In this paper, the pipe weld is simplified into a plane strain model. For Mode-I crack, the parameter $G_{I C}$ under critical plane strain is expressed as

$$
G_{I C}=\left(1-\mu^{2}\right) \frac{\mathrm{K}_{I C}^{2}}{E}
$$

The basic idea of VCCT is that the work of the crack developing from a to $a+\Delta a$ is equivalent to the work of the crack closing from $a+\Delta a$ to a. Figure 4 shows a crack with the length " $\mathrm{a}$ " and the virtual increment " $\Delta a$ ". The closure integral of Mode-I crack is

$$
G_{I} \cong \lim \frac{1}{2 \triangle a} \int_{0}^{\Delta d} \sigma_{\mathrm{yy}}^{(1)}(\Delta a-r, 0) \Delta v^{(2)}(r, \pi) d r
$$

where $\sigma_{\mathrm{yy}}^{(1)}$ is the stress component at crack tip when the length of the crack is d, $\Delta v^{(2)}$ is the relative opening displacement of the point in the virtual crack plane, $\Delta a$ is the virtual crack increment, and $G_{I}$ is the component of the strain release rate of Mode-I crack.

In consideration of the FEM meshes near the crack tip, the work done by the stress in the virtual crack line equals the product of the node force and its displacement. The basic hypothesis of VCCT is that the opening displacement at the virtual crack tip is close to that at the initial crack tip. Therefore, for the FEM meshing model in Figure 5, the strain energy release rate is

$$
G_{I} \cong \frac{F_{\mathrm{y} 1} \Delta v_{3,4}}{2 \Delta a}
$$

where $F_{y 1}$ is the force at node 1 and $\Delta v_{3,4}$ is the relative vertical displacement between node 3 and node 4 .

By comparing the energy release rate $G_{I}$ obtained by FEM computation with the critical energy release rate of the material $G_{I C}$, the crack propagation in pipe welds could be predicted: if $G_{I} \geq G_{I C}$, then the crack will grow.

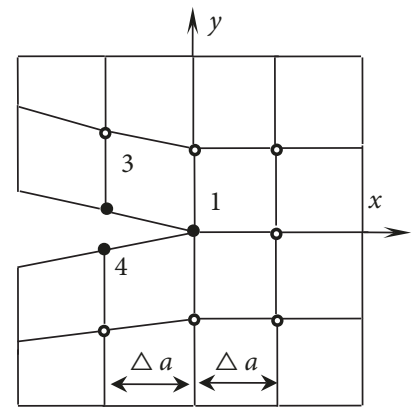

FIGURE 5: Diagram of the release rate of strain energy calculated by the virtual crack closure method.

\subsection{Load Application and Boundary Conditions}

3.3.1. Dynamic Application of the Fluid Permeation Pressure. (1) The fluid pressure in the final loading step which was applied on the inner wall of pipeline was $P_{\text {end }}\left(P_{\text {end }}=30 \mathrm{MPa}\right)$.

(2) During the solution process, the automatic load step is turned on, and the fluid pressure applied at each load step was $P_{\mathrm{i}}$. In the first load step, apply the fluid pressure $P_{i}=P_{\text {end }} / 1000$. If it converges easily, $P_{i}=P_{\text {end }} /(100 \sim 1000)$, while if it converges slowly, $P_{i}=P_{\text {end }} /\left(1000 \sim 10^{7}\right)$.

(3) $P_{\text {end }}$ was applied on the TARGE169 unit and CONTA171 unit. As shown in Figure 6, the initial points (A and $\mathrm{B}$ ) and final points $(\mathrm{C}$ and $\mathrm{D})$ of the fluid osmotic pressure were defined. TARGE169 unit and CONTA171 unit were at the same position.

(4) In the solving process, the internal crack growth length $\left(L_{\mathrm{s}}\right)$ was verified and the fluid osmotic pressure $\left(P_{\mathrm{s}}\right)$ was applied.

If $L_{s}=0$, no internal growth was observed. The fluid osmotic pressure at the initial internal crack length $\left(L_{\mathrm{b}}\right)$ was as follows:

$$
P_{\mathrm{s}}=P_{i}, \quad\left(L_{\mathrm{s}}=0, L \in\left(0, L_{\mathrm{b}}\right)\right)
$$

where $L$ is the radial distance variable from the inner wall at the internal crack to the weld center at the outer wall of pipelines.

The fluid osmotic pressure at $L_{\mathrm{p}}$ was

$$
P_{\mathrm{s}}=0, \quad\left(L_{\mathrm{s}}=0, L \in\left(L_{\mathrm{b}}, L_{\mathrm{b}}+L_{\mathrm{p}}\right)\right)
$$

If $L_{s}>0$, the internal crack began to propagate. The fluid osmotic pressure at the internal crack $L_{\mathrm{b}}+L_{\mathrm{s}}$ was

$$
P_{\mathrm{s}}=P_{i}, \quad\left(L_{\mathrm{s}}>0, L \in\left(0, L_{\mathrm{b}}+L_{\mathrm{s}}\right)\right)
$$

The fluid osmotic pressure at the nongrowth position $\left(L_{\mathrm{p}}-L_{\mathrm{s}}\right)$ of preexpansion route was

$$
P_{\mathrm{s}}=0, \quad\left(L_{\mathrm{s}}>0, L \in\left(L_{\mathrm{b}}+L_{\mathrm{s}}, L_{\mathrm{b}}+L_{\mathrm{p}}\right)\right)
$$

In (6) (9), the fluid osmotic pressure $\left(P_{s}\right)$ and fluid pressure on the inner pipeline wall $\left(P_{i}\right)$ formed the fluid pressure load $\left(F_{P i(u)}\right)$ in the process of internal crack growth. The magnetic load $\left(F_{\operatorname{mg}(u)}\right)$ was overlooked, and the load 


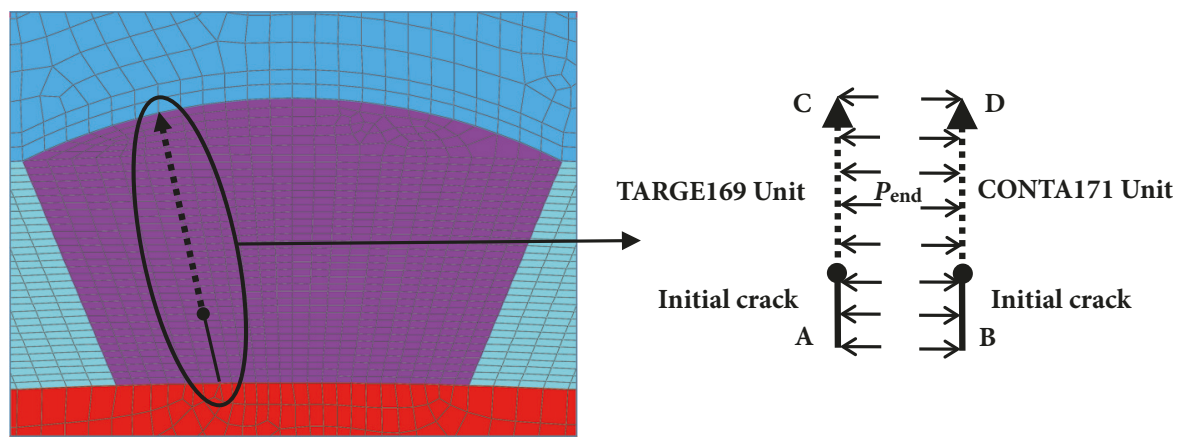

FIGURE 6: Diagram of the starting and ending points for the application of osmotic pressure.

vector of the node $\left(F_{(u)}\right)$ in (1) was formed again in each loading step. The dynamic application of fluid pressure load was accomplished, which would further influence the weld structural deformation $(u)$. In this way, the bidirectional fluid-solid coupling between the fluid in the pipeline and weld structure was realized.

3.3.2. Application of Displacement Boundary Conditions. The displacement constraint was applied. Radial and circumferential degrees of freedom (DOFs) were restrained on $0^{\circ}$ and $180^{\circ}$ circumferential directions of pipelines, while the annual DOF was restrained on the $270^{\circ}$ circumferential direction of pipelines.

3.3.3. Application of Magnetic Field Loads and Magnetic Field Boundary Conditions. (1) The coercivity of permanent magnet was $919000 \mathrm{~A} / \mathrm{m}$ and it was applied along the height of permanent magnet.

(2) The far-field unit was used, and only computational domain with finite size was required to be established. INFIN110 far-field unit was chosen and far-field boundaries were applied surrounding the computational domain. The condition of convergence was L2 norm $\|\{R\}\|_{2}=\left(\sum \mathrm{R}_{\mathrm{i}}^{2}\right)^{1 / 2}$, as defaulted in FEM software.

\section{Fluid-Solid-Magnetic Multifield Coupling Algorithm}

The flowchart of the proposed fluid-solid-magnetic coupling algorithm is shown in Figure 7. The major steps are as follows.

(1) Construct the fluid-solid-magnetic multiphysical field model of internal crack growth in the weld of pipelines.

(2) Construct the fluid-solid-magnetic multifield mathematical model of internal crack growth in the weld of pipelines.

(3) If $G_{I} \geq G_{I C}$, the crack grows, $L_{\mathrm{s}}>0$; then calculate internal crack growth in the weld of pipelines.

(4) Reconstruct computational domain grid surrounding internal cracks in the weld of pipelines.

(5) Analyze the MFL field in the internal crack growth process.

(6) Compare the internal crack expansion length $\left(L_{\mathrm{s}}\right)$ and preexpansion route length $\left(L_{\mathrm{p}}\right)$, and judge whether the weld in pipelines is broken. The sketch map of $L_{\mathrm{s}}$ and $L_{\mathrm{p}}$ is shown in Figure 8.

(a) If $L_{\mathrm{s}}<L_{\mathrm{p}}$, the weld remains unbroken and repeat Steps (3) (6). The loading step is $i=i+1$. Repeat the calculation analysis.

(b) If $L_{\mathrm{s}} \geq L_{\mathrm{p}}$, the weld is broken. End the calculation.

(7) Postprocess the fluid-solid-magnetic multifield coupling results of internal crack growth in the weld of pipelines.

\section{Numerical Example}

5.1. Calculation Parameters. The excitation structure contains a closed magnetic circuit consisting of the permanent magnet, armature, pole shoe, air gap, and pipeline weld. The dimensions and materials of the magnetization structure are presented in Table 1 . The parameters of the pipe weld and the initial parameters of the internal crack are shown in Table 2. In this paper, the internal crack distribution along the radial inner wall was calculated by taking the position of $1 / 2$ arc length from the fusion line to the center of the welding path as a numerical example (see Figure 1). Q235 steel was used as the material of the pipe, and the constitutive model of the pipe weld material was a linear strengthening elastic-plastic model, and the mechanical properties of this material are shown in Table 3.

5.2. Internal Crack Growth. The internal crack growth was computed by the VCCT internal crack growth algorithm and the energy release rate criterion in fracture mechanics. At the current loading step $i$, the energy release rate $\left(G_{i}\right)$ at crack tip was calculated. And then, compared with the critical energy release rate $\left(G_{\mathrm{IC}}\right)$ of the selected pipeline material, if $G_{i} \geq G_{\mathrm{IC}}$, the internal cracks propagated.

Figure 9(a) presents the distribution of the fluid osmotic pressure in the calculation process of the internal crack propagation. The load step is $i=68$, and the fluid osmotic pressure is $P_{i}=P_{\mathrm{s}}=13.7511 \mathrm{MPa}$. However, when the fluid osmotic pressure is ignored $\left(P_{\mathrm{s}}=0\right)$, the distribution of the fluid pressure is displayed in Figure 9(b). And the load step is $i=58$ and the fluid pressure is $P_{i}=14.6475 \mathrm{MPa}$.

The result of the load step (progressive application of the fluid osmotic pressure) in the crack propagation was extracted, and the node coordinates were updated according 


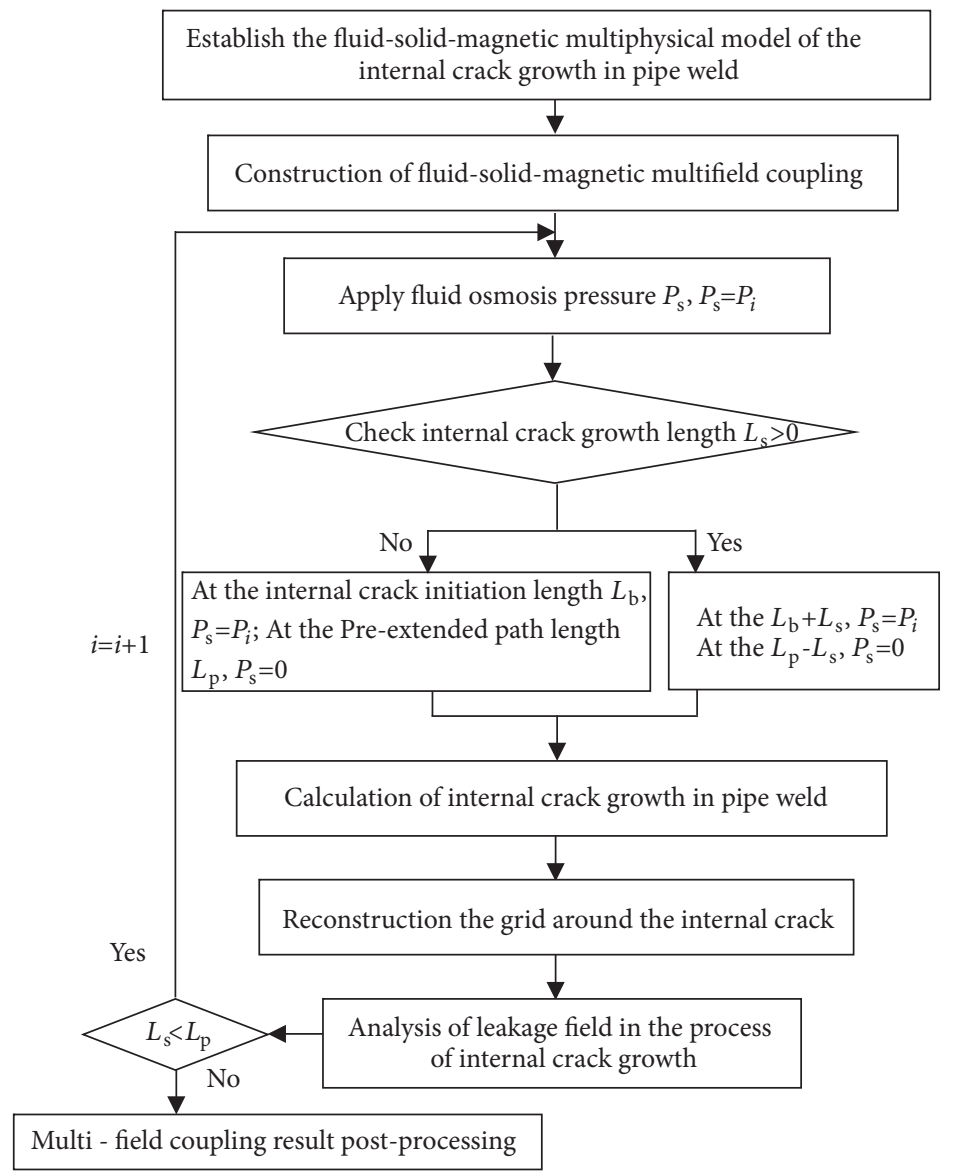

FIGURE 7: Flow chart of the fluid-solid-magnetic coupling algorithm.

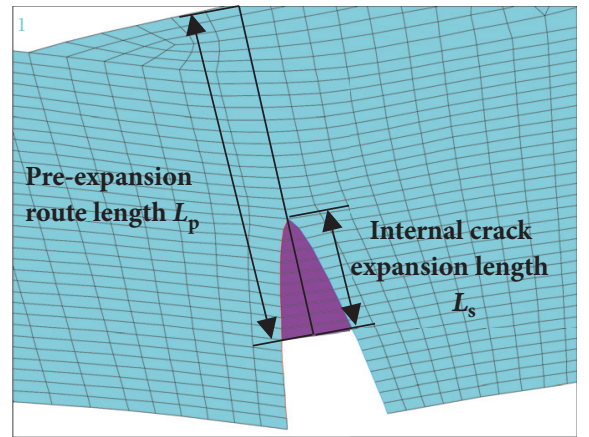

FIGURE 8: Sketch map of $L_{\mathrm{s}}$ and $L_{\mathrm{p}}$.

to the deformation amount of the inner wall structure in pipelines during the internal crack propagation. The internal crack growth process is exhibited in Figure 10.

With the internal crack growth on inner wall of pipelines, the fluid penetrated into cracks and fluid osmotic pressure was generated, resulting in the acceleration of the internal crack propagation and the deformation of the pipeline weld structure. Once the structure of the pipe weld was deformed, the internal cracks were also extended synchronously and the fluid penetrated further, which affected the distribution
TABLE 1: Magnetized structural dimensions and materials.

\begin{tabular}{llll}
\hline Dimensions & & \multicolumn{2}{c}{ Materials } \\
\hline$L_{f}$ & $174 \mathrm{~mm}$ & magnet & Nd-Fe-B \\
\hline$L_{g}$ & $70 \mathrm{~mm}$ & armature & armco iron \\
$H_{a}$ & $25 \mathrm{~mm}$ & & \\
\hline$H_{m}$ & $15 \mathrm{~mm}$ & pole shoe & armco iron \\
$H_{p}$ & $20 \mathrm{~mm}$ & & \\
\hline
\end{tabular}

of the fluid permeation pressure and further accelerated the expansion of the internal cracks. Thus, the bidirectional fluidsolid coupling process was achieved between the internal fluid and weld structure of pipelines.

5.3. Gridding Reconstruction for the Internal Crack. The key points generated at the crack profile nodes according to the opening distance of internal cracks $L_{\mathrm{o}}$ and extended length $L_{\mathrm{s}}$ were connected into a surface, which was then meshed and given the properties of air units. Thus, the air gridding located at the crack was reconstructed. The gridding reconstruction is a process of dynamic internal crack growth and dynamic gridding reconstruction, and it is the key technology of the fluid-solid-magnetic multifield coupling 
TABle 2: Pipe weld parameters.

\begin{tabular}{|c|c|c|c|}
\hline Material parameter & Geometric di & & loading \\
\hline \multirow{6}{*}{ Q235 } & Pipe diameter $D$ & $400 \mathrm{~mm}$ & \multirow{6}{*}{$P_{\text {end }}=30 \mathrm{MPa}$} \\
\hline & Pipe wall thickness $W$ & $8 \mathrm{~mm}$ & \\
\hline & Weld width $W_{w}$ & $18 \mathrm{~mm}$ & \\
\hline & Weld reinforcement height $W_{r}$ & $2 \mathrm{~mm}$ & \\
\hline & Initial length of internal crack $L_{b}$ & $2 \mathrm{~mm}$ & \\
\hline & Pre-expansion route length $L_{p}$ & $8 \mathrm{~mm}$ & \\
\hline
\end{tabular}

TABLE 3: Mechanical properties of Q235 steel.

\begin{tabular}{lccccc}
\hline $\begin{array}{l}\text { Elastic Modulus } \\
\text { E/GPa }\end{array}$ & $\begin{array}{c}\text { Poisson ratio } \\
\mu\end{array}$ & $\begin{array}{c}\text { Yield strength } \\
\sigma_{s} / \mathrm{MPa}\end{array}$ & $\begin{array}{c}\text { Tangent } \\
\text { modulus } \\
E_{1} / \mathrm{MPa}\end{array}$ & $\begin{array}{c}\text { Fracture } \\
\text { toughness } \\
K_{I C} / \mathrm{MPa} \sqrt{\mathrm{m}}\end{array}$ & $\begin{array}{c}\text { Critical strain energy } \\
\text { release rate of plane } \\
\text { strain model } \\
G_{I C} /(\mathrm{N} / \mathrm{mm})\end{array}$ \\
\hline 212 & 0.288 & 235 & 6000 & 120.7 & 63.02 \\
\hline
\end{tabular}

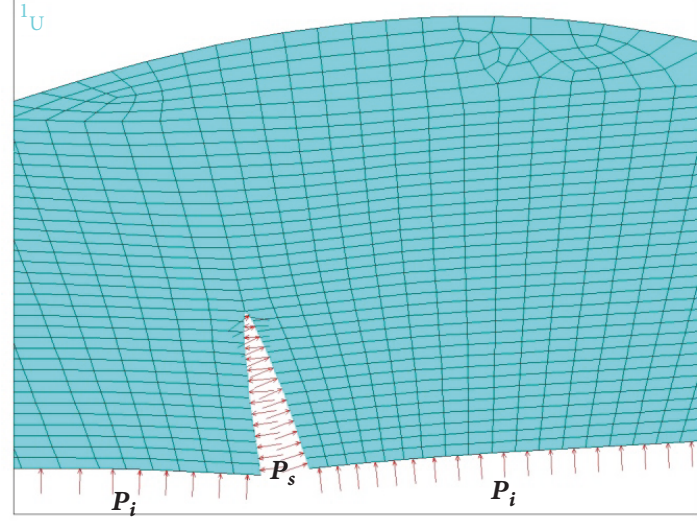

(a) Considering the fluid osmotic pressure

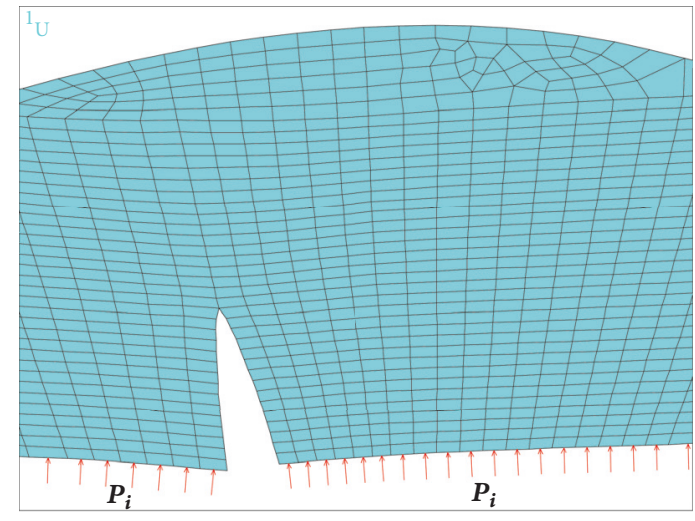

(b) Without considering the fluid osmotic pressure

FIGURE 9: With considering and without considering the fluid osmotic pressure.

algorithm for the internal crack growth in the weld of oil and gas pipelines. The gridding of the fluid domain inside the pipelines and in the crack of the weld was reconstructed according to the deformation volume of the weld and inner wall structure during the internal crack growth under the action of fluid-structure interaction. Besides, the gridding of the outer space of the weld and surrounding air domain of excitation structure was also reconstructed according to the same deformation under the action of fluid-structure interaction. The reconstructed gridding maps are shown in Figure 11. After the mesh reconstruction for fluid domain in pipelines and air domain outside the pipelines, the magnetic stiffness matrix $\left(\boldsymbol{K}_{\mathrm{m}(u)}\right)$ in (1) was regenerated in each loading step, implying that $\boldsymbol{K}_{\mathrm{m}(\boldsymbol{u})}$ is related to $\boldsymbol{u}$. Thus, the coupling of unidirectional magnetic structural was implemented.

\subsection{Analysis on Fluid-Solid-Magnetic Coupling Results}

5.4.1. Analysis on the Influence of Structural Deformation. Based on the internal crack growth and reconstruction of each loading step, the magnetic pole direction in the excitation structure was set. Thus, the magnetic return path between the weld and excitation structure was formed. The MFL field during internal crack growth in the weld was computed by the nonlinear vector potential method. The opening distance of internal cracks $L_{\mathrm{o}}$ and extended length $L_{s}$ at each loading step ( $i$ ) from the growth beginning to the buckling failure was extracted, and Figures 12 and 13 indicated $P_{i}-L_{\mathrm{o}}$ and $P_{i}-L_{\mathrm{s}}$ curves obtained at the internal cracks could be used to compare the influence of the fluid osmotic pressure $P_{\mathrm{s}}$ on the internal crack growth under condition of considering and not considering the fluid osmotic pressure.

It was observed from Figures 12 and 13 that the opening distance of internal cracks $L_{\mathrm{o}}$, extended length $L_{\mathrm{s}}$ obtained at the last loading step before the buckling failure was $L_{o}^{P_{\mathrm{S}}}=3.6506 \mathrm{~mm}$ and $L_{\mathrm{s}}^{P_{\mathrm{S}}}=3.1892 \mathrm{~mm}$, respectively, when the fluid osmotic pressure $P_{\mathrm{s}}$ was applied, whereas the opening distance of internal cracks $L_{0}$ and extended length $L_{\mathrm{s}}$ obtained without the fluid osmotic pressure $P_{\mathrm{s}}$ was $L_{o}^{P_{\mathrm{i}}}=3.3909 \mathrm{~mm}$ and $L_{\mathrm{s}}^{P_{\mathrm{i}}}=3.0009 \mathrm{~mm}$, respectively. This phenomenon illustrated that the opening distance of internal 


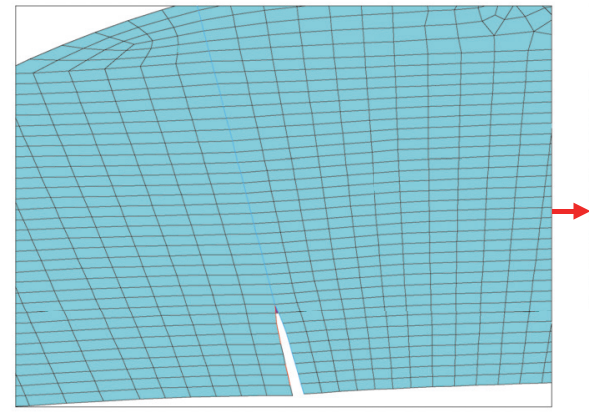

(a) Load step $\boldsymbol{i}=\mathbf{5 4}, \boldsymbol{P}_{\boldsymbol{i}}=\boldsymbol{P}_{\boldsymbol{s}}=12.5127 \mathrm{MPa}$, $l_{\boldsymbol{o}}=0.2882 \mathrm{~mm}, l_{s}=0.2391 \mathrm{~mm}$

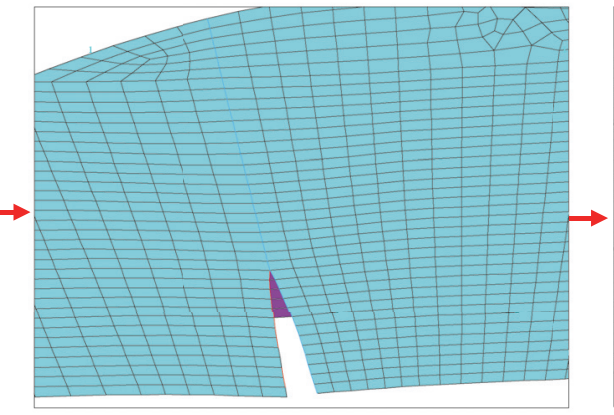

(b) Load step $\boldsymbol{i}=\mathbf{6 6}, \boldsymbol{P}_{\boldsymbol{i}}=\boldsymbol{P}_{\boldsymbol{s}}=13.7256 \mathrm{MPa}$, $\boldsymbol{l}_{\boldsymbol{o}}=0.8223 \mathrm{~mm}, \boldsymbol{l}_{\boldsymbol{s}}=1.20994 \mathrm{~mm}$

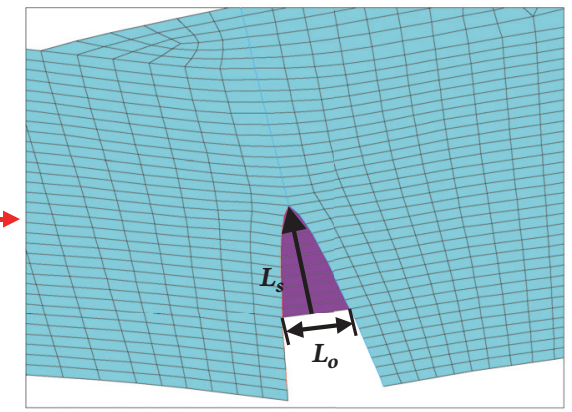

(c) Load step $i=72, \boldsymbol{P}_{\boldsymbol{i}}=\boldsymbol{P}_{\boldsymbol{s}}=13.7643 \mathrm{MPa}$, $l_{\boldsymbol{o}}=2.5404 \mathrm{~mm}, l_{\boldsymbol{s}}=2.6875 \mathrm{~mm}$

Figure 10: Process of the internal crack growth.

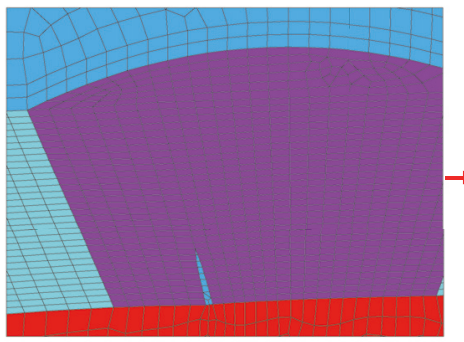

(a) Load step $i=54$

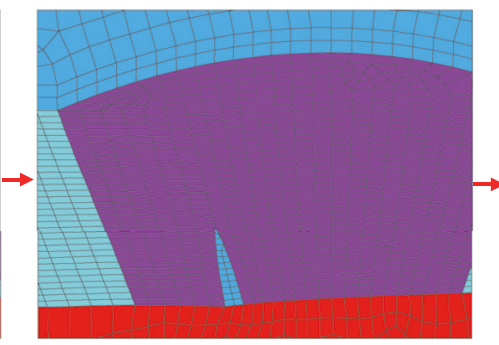

(b) Load step $i=66$

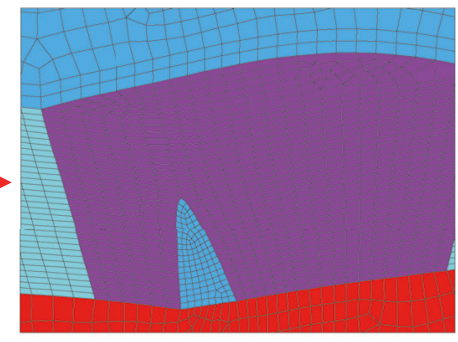

(c) Load step $i=72$

FIGURE 11: Gridding reconstruction for the internal crack.

cracks and extended length was large, when the fluid osmotic pressure $P_{\mathrm{s}}$ was considered.

Besides, the energy release rate $G_{I}$ at the crack tip was calculated, namely, the command flow programmed by using the finite-element software under different pressures and growth lengths, and the results were displayed in Tables 4 and 5 and Figure 14. It was found that $G_{I}<G_{I C}(63.02 \mathrm{~N} / \mathrm{mm})$, and the internal crack could not expand, when the internal crack entered the stage of unexpanded growth without considering the fluid osmotic pressure. However, if $G_{I} \geq G_{I C}$, the internal crack began to expand and entered the stage of steady-state growth. When the $G_{I}$ value continued to increase, the crack entered the stage of accelerating growth, and it would soon enter the unstable fracture stage. In this stage, only a small load was applied to keep the pipe damaged until it broke. Consequently, the curvilinear trends in Figures 12-14 can characterize the process of crack growth and the risk level of pipelines.

In order to further compare the growth degree of internal cracks under condition of considering and not considering the fluid osmotic pressure, the $L_{\mathrm{s}}$ values of steady-state and accelerating growth stages were fitted from Figures 12 and 13. The fitting curve and equation are obtained in Figure 15 and fitting equation (7) (13).

Fitting equation of the fitting curvel with considering $P_{\mathrm{s}}$ in the stage of steady-state growth is

$$
y=\frac{1}{(40.2349-2.8412 x)} \quad(12.5127 \leq x \leq 13.6434)
$$

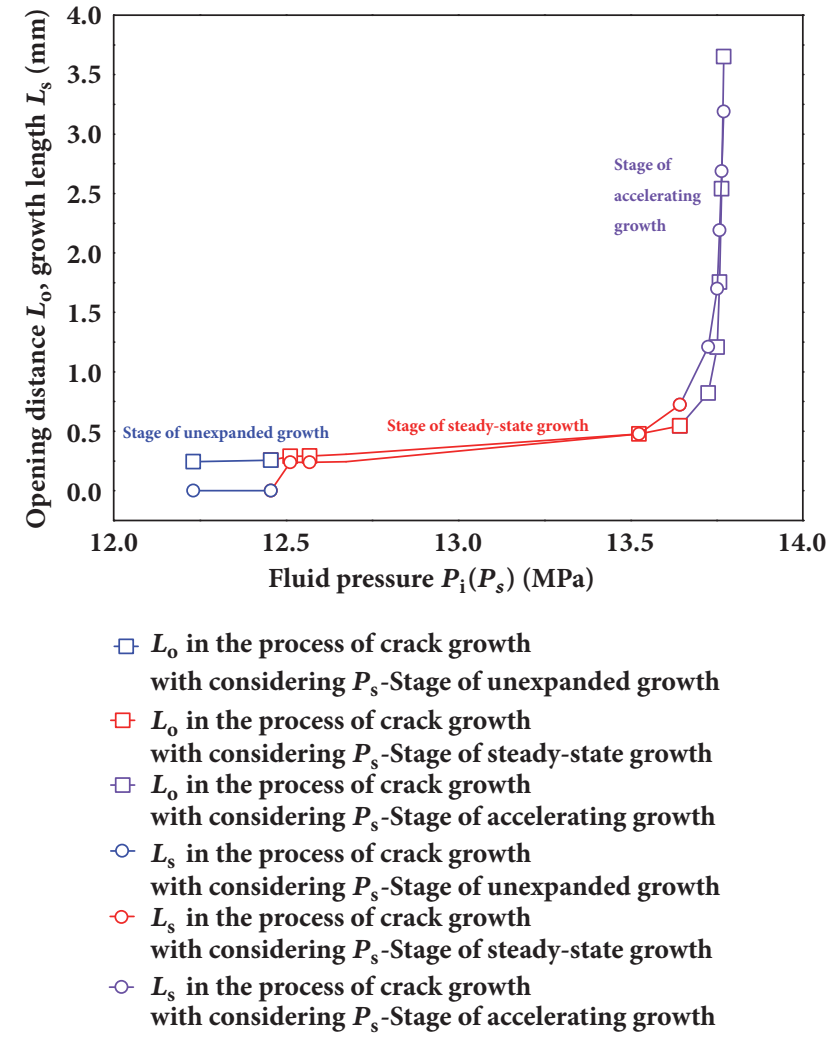

Figure 12: $P_{i}-L_{\mathrm{o}}$ and $P_{i}-L_{\mathrm{s}}$ curves with considering the fluid osmotic pressure. 


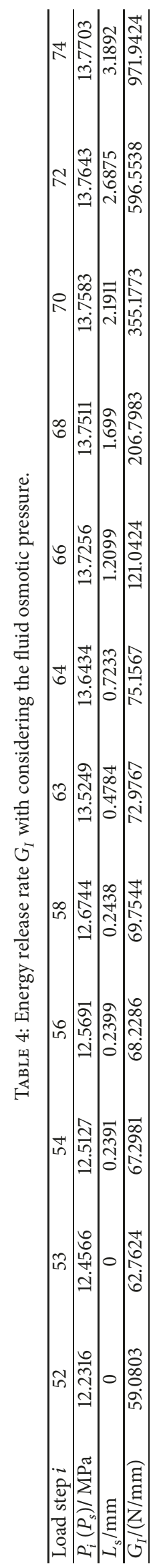




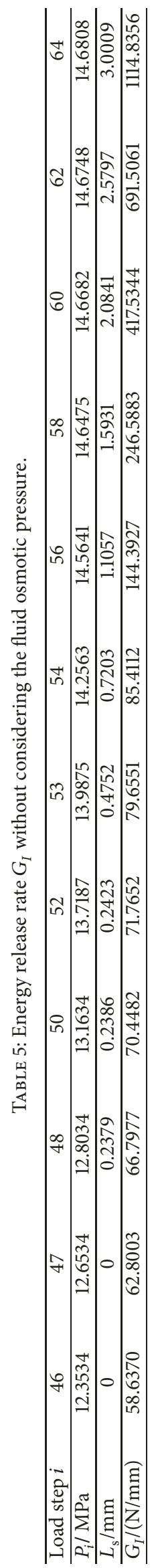




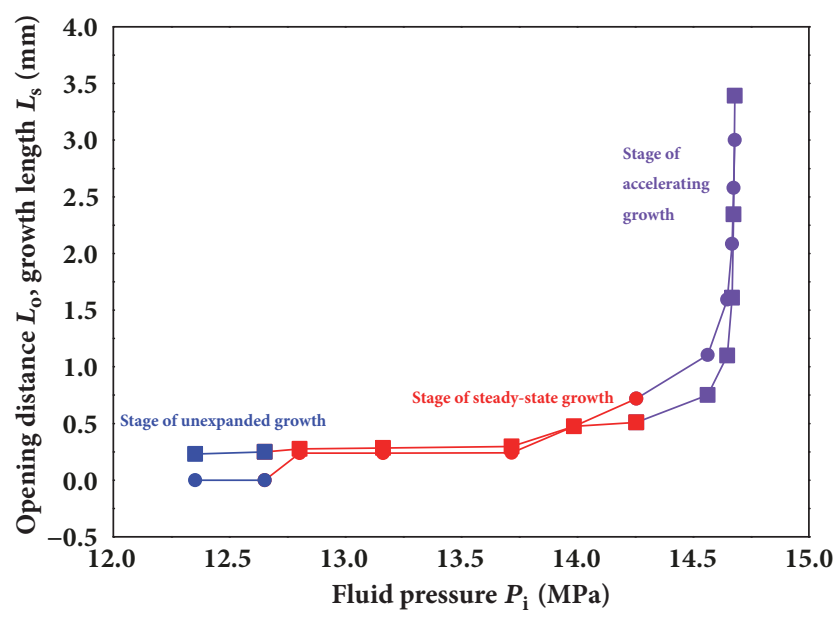

- $L_{0}$ in the process of crack growth without considering $\boldsymbol{P}_{\mathrm{s}}$-Stage of unexpanded growth

$-L_{0}$ in the process of crack growth without considering $\boldsymbol{P}_{\mathrm{s}}$-Stage of steady-state growth

$-L_{0}$ in the process of crack growth without considering $\boldsymbol{P}_{\mathrm{s}}$-Stage of accelerating growth

- $L_{\mathrm{s}}$ in the process of crack growth without considering $\boldsymbol{P}_{\mathrm{s}}$-Stage of unexpanded growth

- $L_{\mathrm{s}}$ in the process of crack growth without considering $\boldsymbol{P}_{\mathrm{s}}$-Stage of steady-state growth

- $L_{\mathrm{s}}$ in the process of crack growth without considering $\boldsymbol{P}_{\mathrm{s}}$-Stage of accelerating growth

Figure 13: $P_{i}-L_{\mathrm{o}}$ and $P_{i}-L_{\mathrm{s}}$ curves without considering the fluid osmotic pressure.

Fitting equation of fitting curve 2 without considering $P_{\mathrm{s}}$ in the stage of steady-state growth is

$$
y=2 \times 2.0637 \mathrm{E}^{-27} e^{(x / 0.2375)}+0.2369
$$

$$
(12.8034 \leq x \leq 14.2563)
$$

Fitting equation of fitting curve 3 with considering $P_{\mathrm{s}}$ in the stage of accelerating growth is

$$
y=\frac{1}{(162.1081-11.7496 x)}
$$

$(13.6434 \leq \mathrm{x} \leq 13.7703)$

Fitting equation of fitting curve 4 without considering $P_{\mathrm{s}}$ in the stage of accelerating growth is

$$
\begin{aligned}
y= & -1.18 \mathrm{E}^{-71} e^{(-x / 0.0992)}+3.2031 \mathrm{E}^{-72} e^{(x / 0.0888)} \\
& +0.5551 \quad(14.2563 \leq \mathrm{x} \leq 14.6808)
\end{aligned}
$$

In order to compare the $L_{\mathrm{s}}$ growth ratios in the same pressure range, ten further ranges were divided from $12.8034 \mathrm{MPa}$ to $13.7703 \mathrm{MPa}$, and the pressure increment delta was set at $\triangle P=0.0967 \mathrm{MPa}$. Thus, the data of $L_{\mathrm{s}}$ growth ratios were obtained at the same pressure and the results were listed in Table 6, and then the comparative histogram was drawn in Figure 16. It was found from Table 6 that $R_{L s}$ values

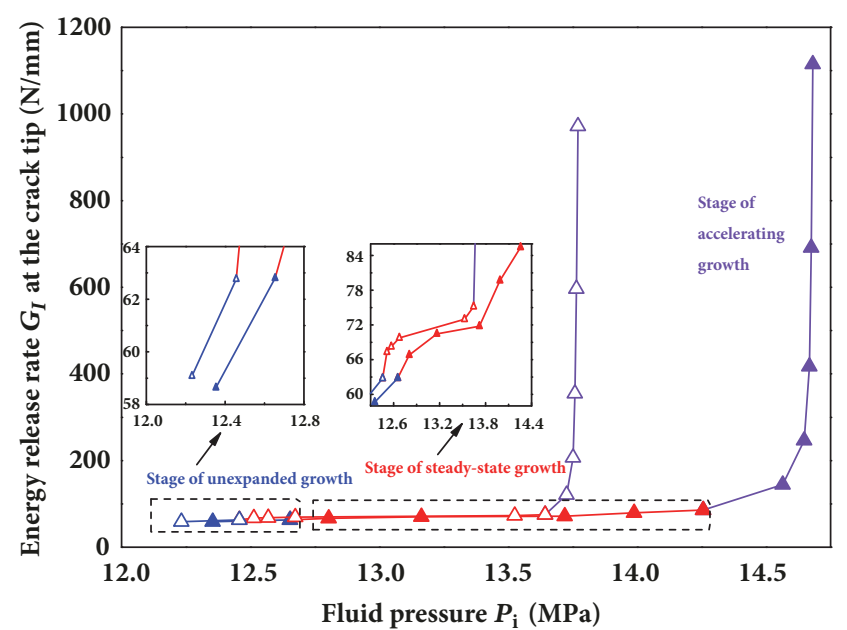

- $G_{I}$-without considering $P_{s}$-Stage of unexpanded growth - $G_{I}$-without considering $P_{s}$-Stage of steady-state growth - $G_{I}$-without considering $P_{s}$-Stage of accelerating growth

$\triangle G_{I}$-with considering $P_{s}$-Stage of unexpanded growth

$-\triangle G_{I}$-with considering $P_{s}$-Stage of steady-state growth

$\neg G_{I}$-with considering $P_{s}$-Stage of accelerating growth

FIGURE 14: $P_{i}-G_{I}$ curves obtained under condition of considering and not considering the fluid osmotic pressure.

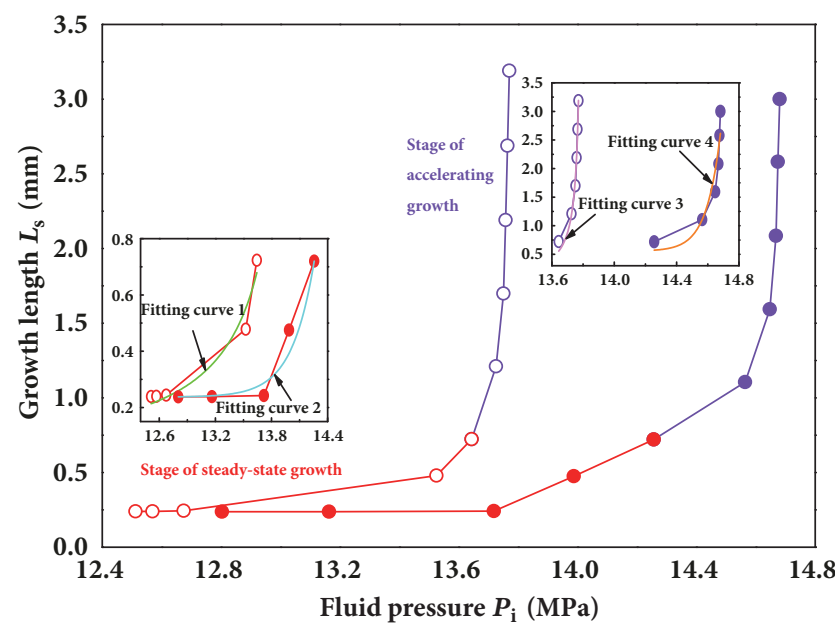

-o- $L_{\mathrm{s}}$-with considering $\boldsymbol{P}_{\mathrm{s}}$-Stage of steady-state growth

-o- $\boldsymbol{L}_{\mathrm{s}}$-with considering $\boldsymbol{P}_{\mathrm{s}}$-Stage of accelerating growth

- $L_{\mathrm{s}}$-without considering $\boldsymbol{P}_{\mathrm{s}}$-Stage of steady-state growth

- $L_{s}$-without considering $\boldsymbol{P}_{\mathrm{s}}$-Stage of accelerating growth

FIGURE 15: $P_{i}-L_{\mathrm{s}}$ curves and fitting curves obtained under condition of considering and not considering the fluid osmotic pressure.

were approximately $1.1 \sim 10.7$, when the pressure increased gradually.

The $L_{\mathrm{s}}$ growth ratio was defined as follows:

$$
R_{L s}=\frac{L_{s}^{P_{s}}}{L_{s}^{P_{i}}}
$$

where $L_{s}^{P_{s}}$ is the $L_{s}$ growth of the internal crack with considering the fluid osmotic pressure and $L_{s}^{P_{i}}$ is the $L_{\mathrm{s}}$ 


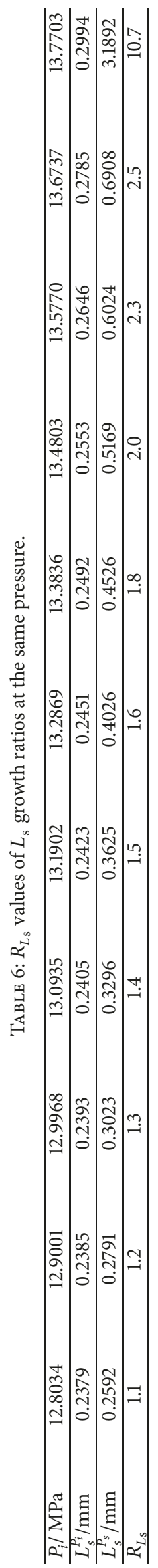




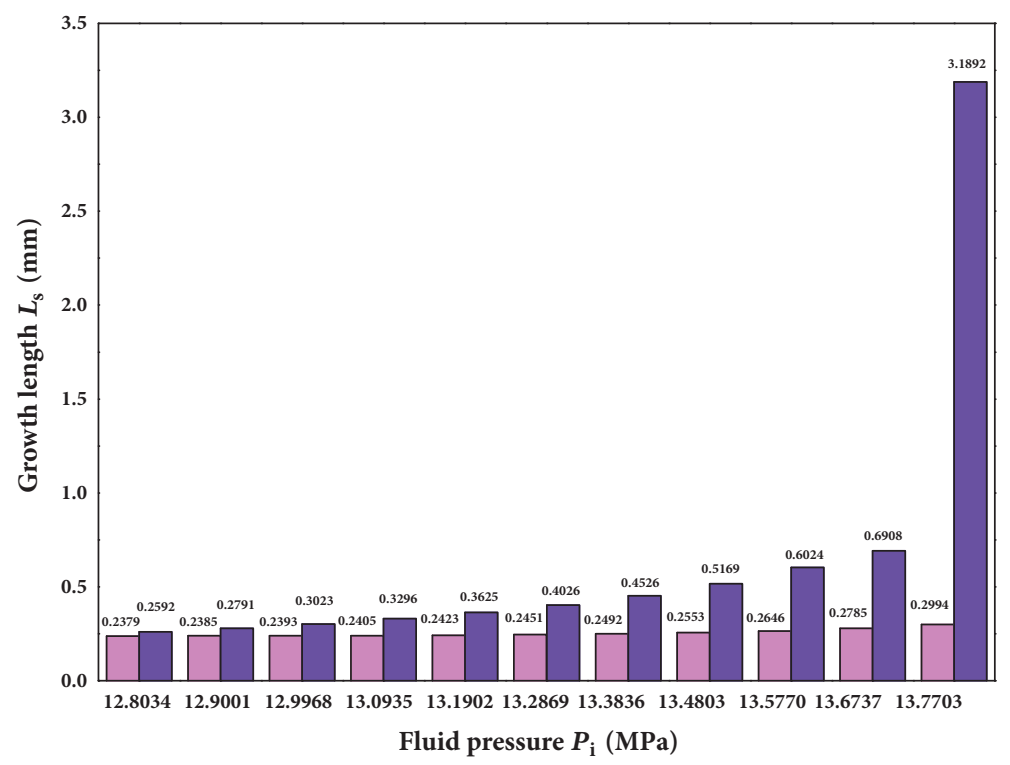

$L_{s}$-without considering $P_{\mathrm{s}}$

$L_{s}$-with considering $P_{s}$

FIGURE 16: Comparative histogram of the crack growth.
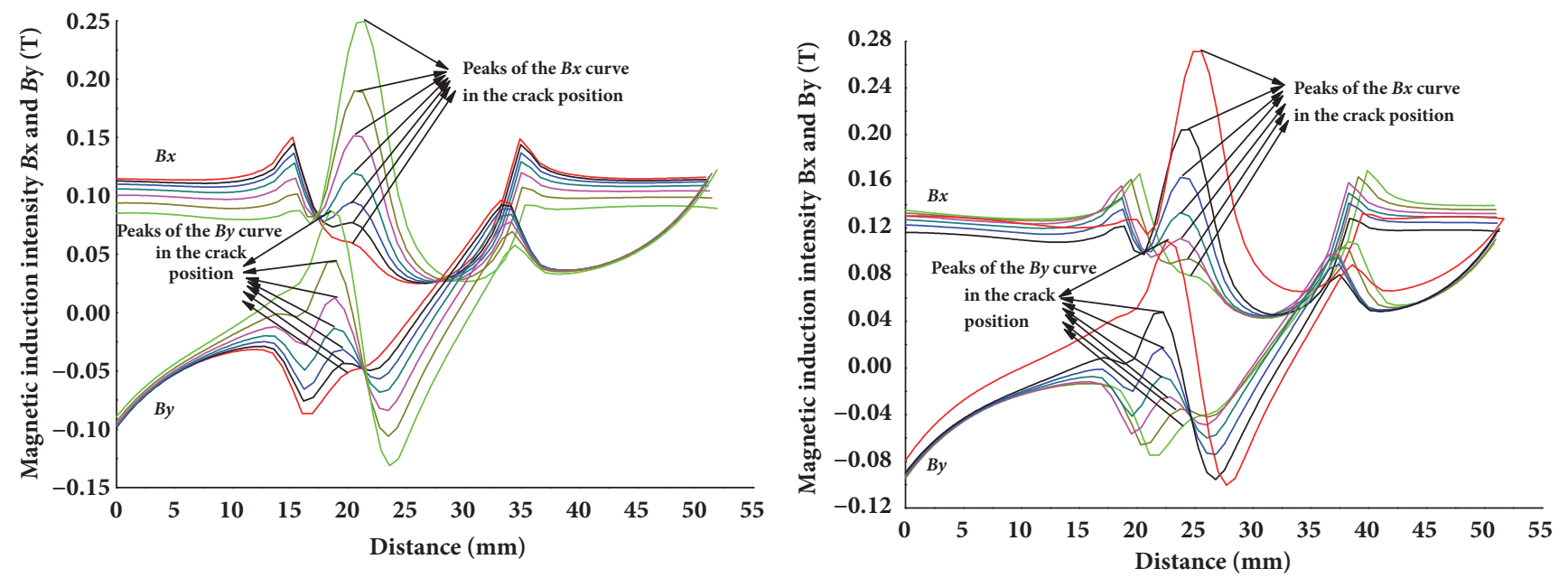

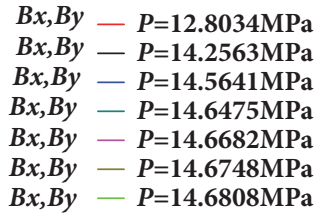

(a) Without considering the fluid osmotic pressure

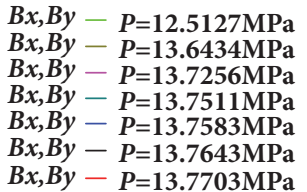

(b) Considering the fluid osmotic pressure

FIGURE 17: Magnetic induction intensity curves.

growth of the internal crack without considering the fluid osmotic pressure.

5.4.2. Analysis on the Influence of Magnetic Field. Figure 17 presents the horizontal component of the magnetic induction intensity $B_{x}$ and vertical component of the magnetic induction intensity $B_{y}$ extracted in the process of the internal crack growth. It was found that the driving force for internal crack growth increased with the progressive dynamic application of the fluid pressure on the inner wall of pipelines. This result could accelerate the internal crack growth and cause the deformation of the weld structures, bringing about the increase of the opening distance $L_{\mathrm{o}}$ and the length of crack growth $L_{s}$. Thus, the distribution of the magnetic field in pipe 


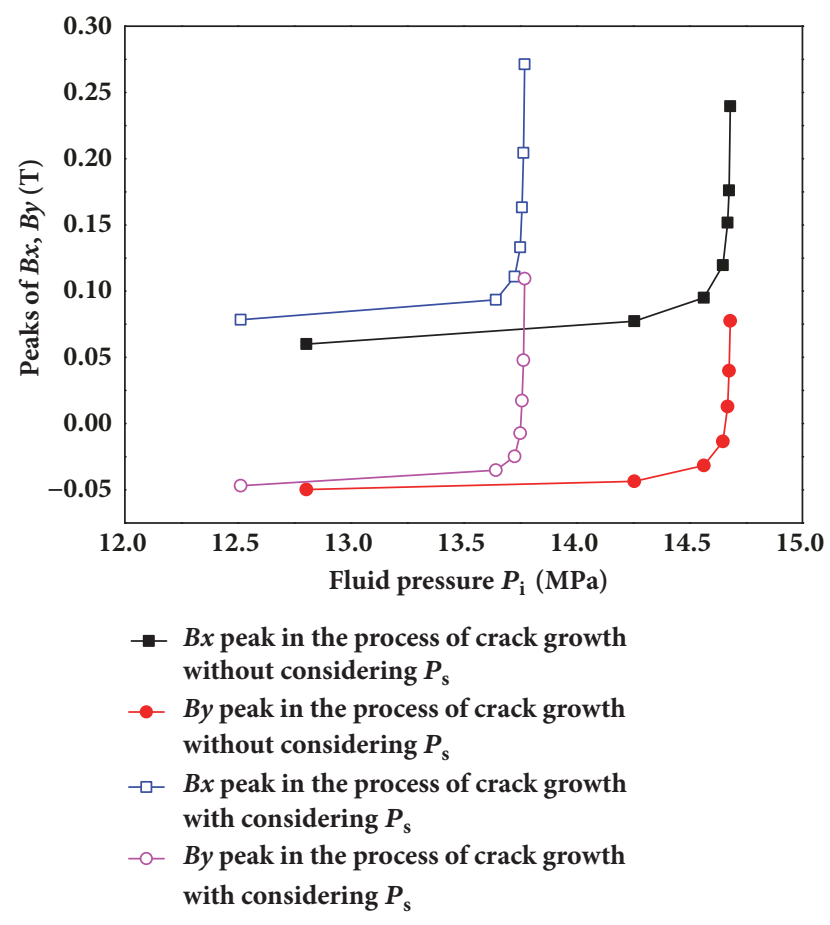

FIgURE 18: $P_{i}-B_{x}$ peak and $P_{i}-B_{y}$ peak curves.

welds during the process of internal crack growth was affected by the deformation of pipe weld structure. Consequently, the horizontal component of the magnetic induction intensity $B_{x}$ and vertical component of the magnetic induction intensity $B_{y}$ showed an increasing trend of whether the fluid osmotic pressure $P_{\mathrm{s}}$ was considered or not.

In order to discuss the influence of the fluid osmotic pressure $P_{\mathrm{s}}$ at internal cracks on magnetic induction intensity of MFL field, the peak horizontal component of the magnetic induction intensity $B_{x}$ and the peak vertical component of the magnetic induction intensity $B_{y}$ were extracted at each loading step (i) from Figure 17. Then the $P_{i}-B_{x}$ peak and $P_{i}-B_{y}$ peak curves were obtained as shown in Figure 18.

It was observed from Figure 18 that the peak horizontal component of the magnetic induction intensity $B_{x}$ and peak vertical component of the magnetic induction intensity $B_{y}$ obtained at the fluid osmotic pressure $P_{s}$ was $B_{x}^{P_{s}}=0.2712 \mathrm{~T}$ and $B_{y}^{P_{\mathrm{S}}}=0.1093 \mathrm{~T}$, respectively. However, $B_{x}$ and $B_{y}$ obtained without considering the fluid osmotic pressure $P_{s}$ were $B_{x}^{P_{1}}=0.2395 \mathrm{~T}$ and $B_{y}^{P_{i}}=0.0776 \mathrm{~T}$, respectively. Consequently, the peak horizontal component of the magnetic induction intensity $B_{x}$ and peak vertical component of the magnetic induction intensity $B_{y}$ detected by the excitation structure was relatively large, when the fluid osmotic pressure $P_{\mathrm{s}}$ was considered.

5.4.3. Further Discussion. It was revealed from Figures 12 , 13 , and 18 that the opening distance of internal cracks $L_{0}$, extended length $L_{s}$, peak horizontal component of the magnetic induction intensity $B_{x}$, and peak vertical component of the magnetic induction intensity $B_{y}$ increased slowly during the steady-state growth stage, while the four eigen values $\left(L_{\mathrm{o}}, L_{\mathrm{s}}, B_{x}\right.$, and $\left.B_{y}\right)$ increased greatly during the accelerating growth stage. Only a small load was applied to keep the pipe damaged until it broke in the last loading step before the buckling failure. In addition, when the fluid pressure $\left(P_{i}\right)$ was the same, $L_{o}, L_{s}, B_{x}$, and $B_{y}$ with considering the fluid osmotic pressure were higher than those without considering the fluid osmotic pressure. The four eigen values $\left(L_{0}, L_{s}, B_{x}\right.$, and $B_{y}$ ) could be used to measure the internal crack growth. And the fluid osmotic pressure accelerated the internal crack growth in pipelines.

It was seen from Tables 4 and 5, the fluid pressure at the beginning of the internal crack growth was $12.8034 \mathrm{MPa}$ without considering the fluid osmotic pressure, whereas the fluid pressure at the beginning of the internal crack growth was $12.5127 \mathrm{MPa}$ with considering the fluid osmotic pressure. This result indicated that the application of the fluid osmotic pressure was more likely to cause the growth of internal cracks. In addition, when the fluid osmotic pressure was considered, the fluid pressure difference (from the beginning of the extended loading step to the loading step before the pipeline was buckling failure) was $P_{\mathrm{d}}^{P_{\mathrm{s}}}=13.7703-$ $12.5127=1.2576 \mathrm{MPa}$. However, when the fluid osmotic pressure was elided, the fluid pressure difference was $P_{\mathrm{d}}^{P_{\mathrm{i}}}=$ $14.6808-12.8034=1.8774 \mathrm{MPa}$. Therefore, the fluid pressure difference was small when the fluid pressure penetration was considered due to the result of $P_{\mathrm{d}}^{P_{\mathrm{s}}}<P_{\mathrm{d}}^{P_{\mathrm{i}}}$. Besides, this result could lead to a large crack propagation velocity and a few extension steps.

It was also found from Tables 4 and 5 that when the fluid osmotic pressure was considered, the $L_{\mathrm{s}}$ values difference (from the beginning of the extended loading step to the loading step before the pipeline was buckling failure) was $L_{\mathrm{s}_{\mathrm{d}}}^{P_{\mathrm{d}}}=3.1892-0.2391=2.9501 \mathrm{~mm}$. However, when the fluid osmotic pressure was elided, the $L_{\mathrm{s}}$ values difference was $L_{\mathrm{s}_{\mathrm{d}}}^{P_{\mathrm{i}}}=3.0009-0.2379=2.763 \mathrm{~mm}$.

In order to measure the speed of crack growth in detail, we defined the internal crack propagation velocity $V_{c}$, which was expressed as follows:

$$
V_{c}=\frac{L_{s_{d}}}{P_{d}}
$$

where $L_{s_{d}}$ is the $L_{\mathrm{s}}$ values difference (from the beginning of the extended loading step to the loading step before the pipeline was buckling failure) and $P_{d}$ is the fluid pressure difference (from the beginning of the extended loading step to the loading step before the pipeline was buckling failure).

It was clear that the internal crack propagation velocity $V_{c}$ could be calculated by using (15). When the fluid osmotic pressure was considered, the internal crack propagation velocity was $V_{c}^{P_{s}}=L_{\mathrm{s}_{\mathrm{d}}}^{P_{\mathrm{s}}} / P_{\mathrm{d}}^{P_{\mathrm{s}}}=2.9501 / 1.2576=$ $2.35 \mathrm{~mm} / \mathrm{MPa}$. However, when the fluid osmotic pressure was elided, the internal crack propagation velocity was $V_{c}^{p_{i}}=$ $L_{\mathrm{s}_{\mathrm{d}}}^{P_{i}} / P_{\mathrm{d}}^{P_{i}}=2.763 / 1.8774=1.47 \mathrm{~mm} / \mathrm{MPa}$. Therefore, the internal crack propagation velocity with considering the fluid 
osmotic pressure was 1.6 times larger than those without considering the fluid osmotic pressure.

When the fluid osmotic pressure was considered, the $L_{\mathrm{o}}$ and $L_{\mathrm{s}}$ values were large, thus resulting in the higher peaks of $B_{x}$ and $B_{y}$. This phenomenon explained the curve variations in Figure 18. When the fluid osmotic pressure was considered, peaks of $B_{x}$ and $B_{y}$ detected by the excitation structure were relatively large due to the large $L_{\mathrm{o}}$ and $L_{\mathrm{s}}$ values with considering the fluid osmotic pressure (see Figure 12).

\section{Conclusions}

(1) When there are some internal cracks in the pipe weld, the fluid carried by the pipe invades the pipe weld where the internal cracks are located. In order to solve this problem, a fluid-solid-magnetic multiphysical field model was established by using the finite-element software. The constitutive model of the pipe weld material was a linear strengthening elastic-plastic model. Based on the mathematical model of fluid-solid-magnetic multifield coupling, the bidirectional fluid-solid coupling and unidirectional magnetic structure coupling caused by the weld deformation were achieved by using the grid reconstruction and dynamic application of the fluid permeation pressure in this paper. And a new fluid-solid-magnetic coupling algorithm for calculating the crack growth in weld of oil and gas pipelines was built.

(2) The fluid-solid-magnetic coupling algorithm considered that the influence of the fluid osmotic pressure was more suitable to predict the engineering practices. According to the coupling results of this example, through the calculation of the energy release rate at the crack tip, the internal crack propagation could be divided into three stages: the stage of unexpanded growth, the stage of steadystate growth, and the stage of accelerating growth. Based on the calculation results, the $R_{L \mathrm{~s}}$ values of $L_{\mathrm{s}}$ growth ratios obtained at the same pressure were approximately 1.1 10.7, and the internal crack propagation velocity with considering the fluid osmotic pressure was 1.6 times larger than those without considering the fluid osmotic pressure. Thus, it can be seen that the velocity of the internal crack growth would increase when the fluid osmotic pressure was considered.

(3) The fluid-solid-magnetic coupling algorithm could be used to characterize the extent of the internal crack growth, and it could also be applied to other conditions, such as internal cracks at different positions of the pipeline weld, different lengths of internal cracks, and multiple cracks in the engineering practice. The algorithm provides a theoretical basis for the detection and evaluation of internal cracks in weld of in-service pipeline by the MFL method and for the reproduction and repair of the pipeline.

\section{Data Availability}

The data used to support the findings of this study are available from the corresponding author upon request.

\section{Conflicts of Interest}

The authors declare that they have no conflicts of interest.

\section{Acknowledgments}

This work was sponsored by the National Natural Science Foundation of China (51607035, 51474072, and 11502051) and Heilongjiang Youth Innovation Talents of Ordinary Undergraduate Colleges and Universities and Heilongjiang Postdoctoral Foundation (LBH-Z16040) and Science and Technology Project of China Petroleum and Chemical Industry Association (2017-11-04) and Research Start-Up Fund of Northeast Petroleum University (rc201732). All of these are gratefully appreciated.

\section{References}

[1] Z. Wu, H. Zhang, J. Liu, Z. Qiu, and M. Zhao, "A PCA and ELM based adaptive method for channel equalization in MFL inspection," Mathematical Problems in Engineering, vol. 2014, Article ID 124968, 8 pages, 2014.

[2] Q. P. Hong, V. T. Bang, D. T. Doan et al., "Highly sensitive planar hall magnetoresistive sensor for magnetic flux leakage pipeline inspection," IEEE Transactions on Magnetics, vol. 54, no. 6, pp. $1-5,2018$.

[3] Y. Du, L. Ma, J.-Y. Zheng, F. Zhang, and A.-D. Zhang, "Consequences prediction and analysis of pipe explosion considering fluid-structure interaction," Journal of Zhejiang University (Engineering Science), vol. 51, no. 3, pp. 429-435, 2017.

[4] W. M. Feng, L. Song, and G. Y. Xiao, "Coupling analysis of fluid-structure interaction in pressure pipes based on ADINA," Engineering Journal of Wuhan University, vol. 42, no. 2, pp. 264267, 2009.

[5] E. Aursand, S. Dumoulin, M. Hammer et al., "Fracture propagation control in $\mathrm{CO} 2$ pipelines: Validation of a coupled fluidstructure model," Engineering Structures, vol. 123, no. 11, pp. 192212, 2016

[6] H. O. Nordhagen, S. Kragset, T. Berstad et al., "A new coupled fluid-structure modeling methodology for running ductile fracture," Computers \& Structures, vol. 94, no. 1, pp. 13-21, 2012.

[7] W. Cui, K. Wang, Q. Zhang et al., "A recognition algorithm to detect pipe weld defects," Tehnicki Vjesnik-Technical Gazette, vol. 24, no. 6, pp. 1969-1975, 2017.

[8] W. Cui, K. Wang, K. Wang, and P. Wang, "Effects of jet rate on microstructure, microhardness, and wear behavior of jet electrodeposited $\mathrm{Ni}-\mathrm{SiC}$ composites," Ceramics International, vol. 44, no. 6, pp. 7214-7220, 2018.

[9] R. Citarella, M. Lepore, V. Shlyannikov, and R. Yarullin, "Fatigue surface crack growth in cylindrical specimen under combined loading," Engineering Fracture Mechanics, vol. 131, pp. 439-453, 2014.

[10] Huifen Peng, Yujie Song, and Ye Xia, "New CZM for Interfacial Crack Growth," Mathematical Problems in Engineering, vol. 2017, Article ID 1415069, 8 pages, 2017.

[11] J. S. Ahn and K. S. Woo, "Delamination of laminated composite plates by p-convergent partial discrete-layer elements with VCCT,' Mechanics Research Communications, vol. 66, pp. 6069, 2015. 
[12] M. Latifi, F. P. Van Der Meer, and L. J. Sluys, "A level set model for simulating fatigue-driven delamination in composites," International Journal of Fatigue, vol. 80, pp. 434-442, 2015.

[13] F. Magi, D. Di Maio, and I. Sever, "Validation of initial crack propagation under vibration fatigue by Finite Element analysis," International Journal of Fatigue, vol. 104, pp. 183-194, 2017.

[14] R. Citarella, G. Cricrì, M. Lepore, and M. Perrella, "DBEM and FEM analysis of an extrusion press fatigue failure," Advanced Structured Materials, vol. 3, pp. 181-191, 2010. 


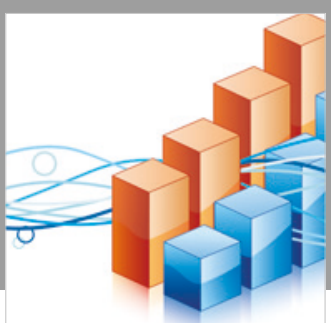

Advances in

Operations Research

\section{-n-m}
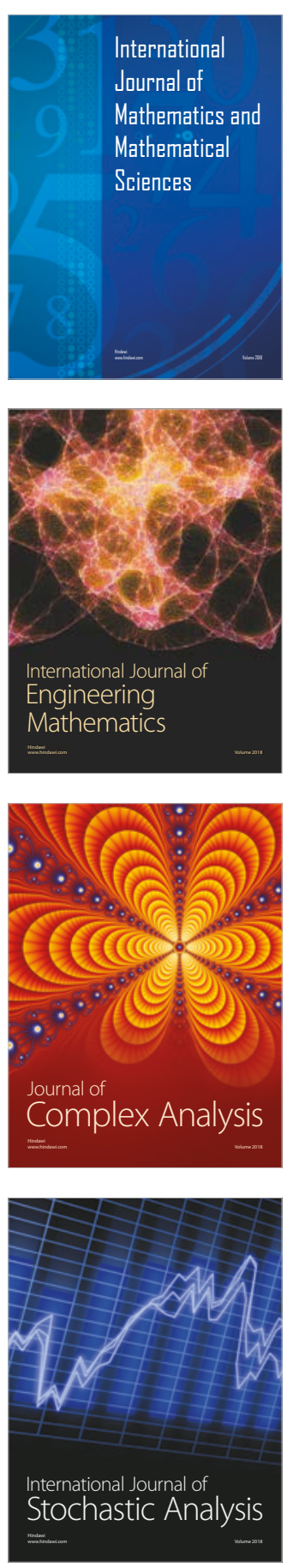
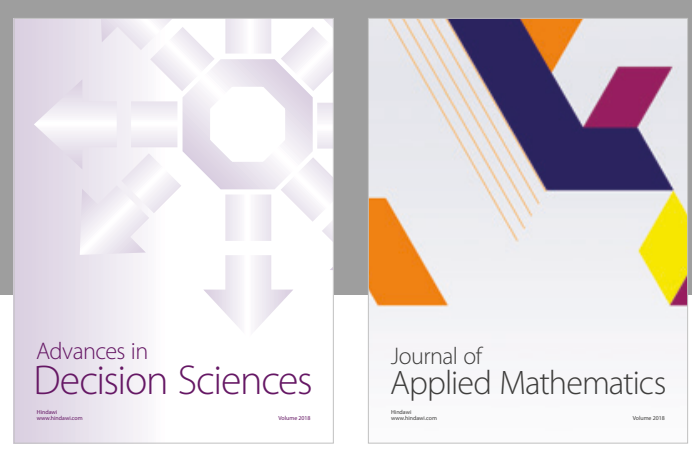

Journal of

Applied Mathematics
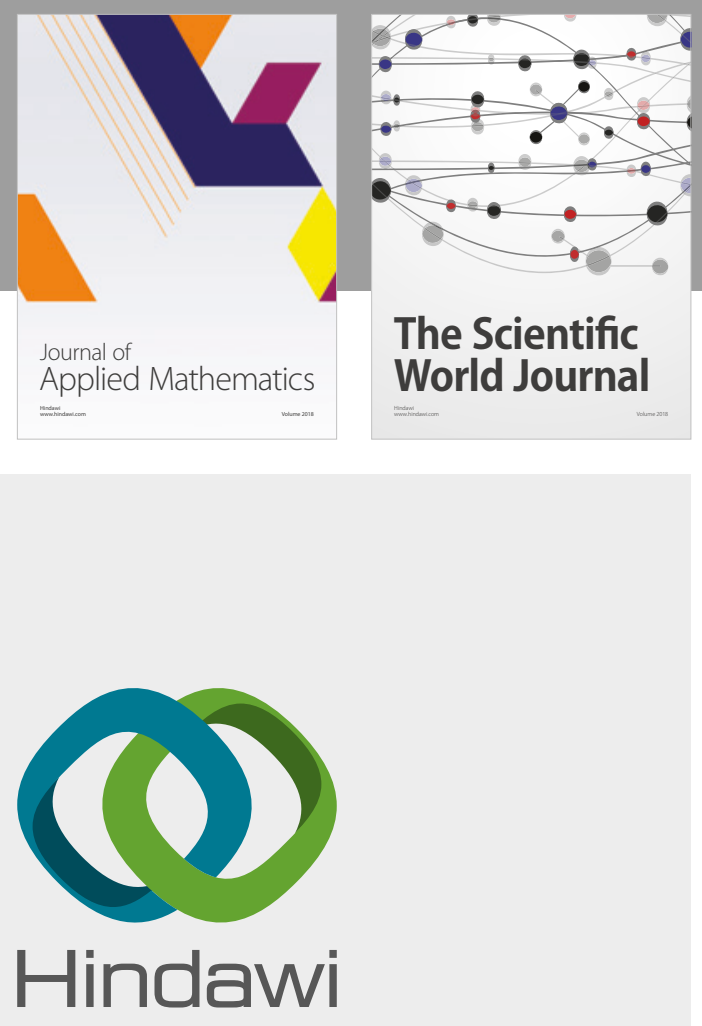

Submit your manuscripts at

www.hindawi.com

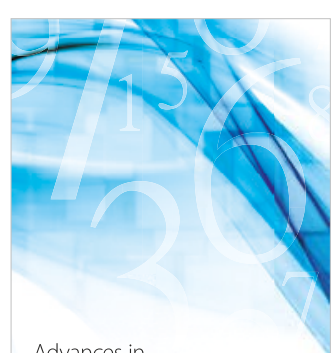

Advances in
Numerical Analysis
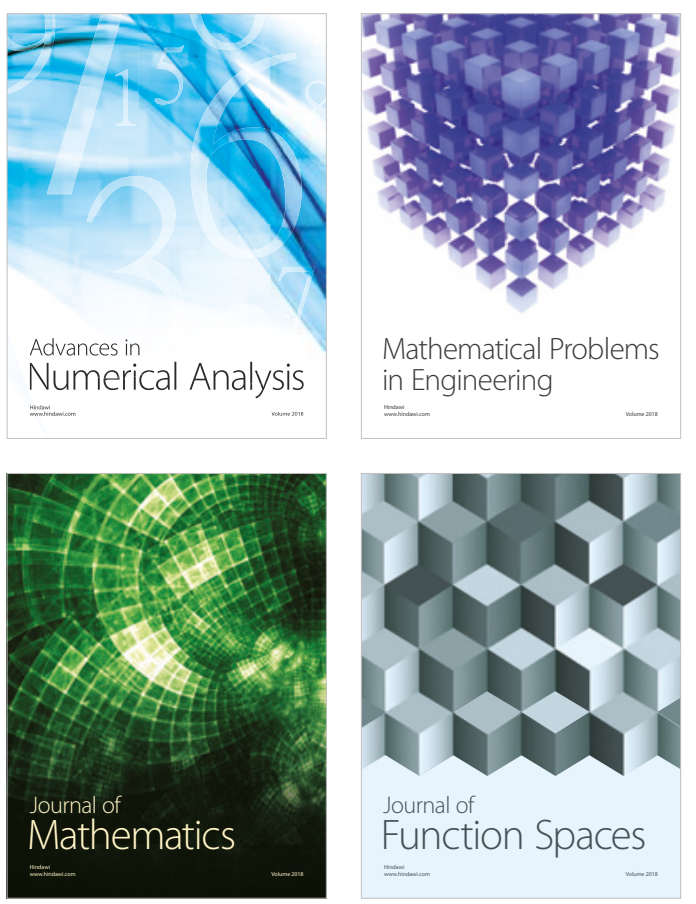

Mathematical Problems in Engineering

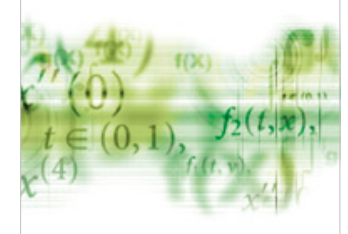

International Journal of

Differential Equations

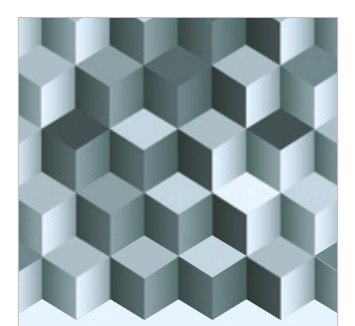

Journal of

Function Spaces

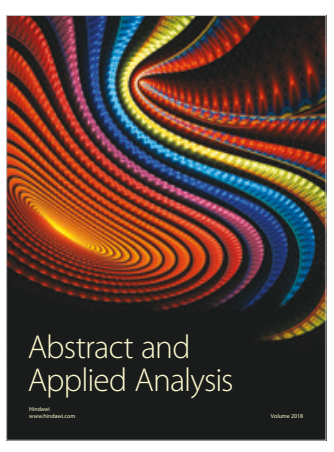

The Scientific

World Journal

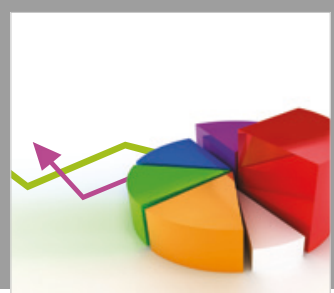

Journal of

Probability and Statistics
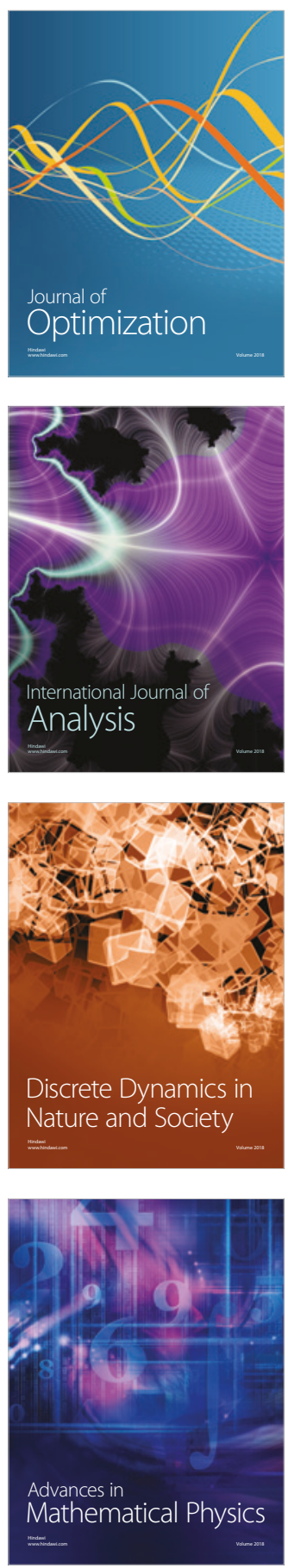